
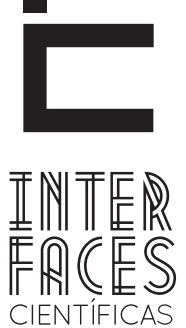

EXATAS E TECNOLÓGICAS

\title{
ROTATIVIDADE DE PESSOAL: UM ESTUDO DE CASO EM UMA EMPRESA DO RAMO DA CONSTRUÇÃO CIVIL
}

\section{RESUMO}

O setor de construção civil vem enfrentando, nos últimos anos, diversos problemas quanto à falta de mão de obra qualificada, ocasionando a rotatividade de pessoal que, em função disso está buscando se aperfeiçoar cada dia mais para se manter no mercado. 0 objetivo geral da presente pesquisa é identificar as principais causas do elevado índice de rotatividade no setor, uma vez que esta gera transtornos e prejuízos para as organizações, no que diz respeito ao elevado custo com admissões e demissões e o impacto da falta e desqualificação da mão de obra hoje disponível no mercado. Esta pesquisa caracteriza-se como bibliográfica e estudo de caso realizado junto aos canteiros de obras e no setor de recursos humanos de uma empresa no setor de construção civil, atuante no município de Bagé/RS e Região, com a participação de vinte e oito colaboradores por meio de questionário aplicado. Para enfrentar esta dificuldade, é de grande ênfase que as organizações mantenham uma administração apropriada de recursos humanos e gestão de pessoas, pois esta possui grande contribuição na tomada de decisões tanto por parte do empregador quanto do colaborador.

\section{PALAVRAS-CHAVE}

Gestão de Pessoas. Rotatividade de Pessoal. Construção civil. 


\section{ABSTRACT}

The construction industry is facing many problems in recent years about the lack of skilled labor, leading to staff turnover which, according to that is seeking to improve every day more to stay on the market. The overall objective of this research is to identify the main causes of high turnover in the sector, since this creates inconvenience and loss for organizations, with regard to the high cost of hiring and layoffs and the impact of the misconduct and the disqualification of labor force on the market today. This research is characterized as literature and case study carried out to construction sites and in the human resources

\section{RESUMEN}

La industria de la construcción se enfrenta a muchos problemas en los últimos años por la falta de mano de obra calificada, lo que lleva a la rotación de personal que, de acuerdo con que está tratando de mejorar cada día más para permanecer en el mercado. El objetivo general de esta investigación es identificar las principales causas de la alta rotación en el sector, ya que crea incomodidad y pérdida de las organizaciones, en relación con el alto costo de la contratación y los despidos y el impacto de la falta y la descalificación mano de obra en el mercado hoy. Esta investigación se caracteriza por la literatura y estudio de caso llevado a cabo las obras de construc- department of a company in the construction sector that the city of Bage / RS and Region, involving twenty-eight employees through of the questionnaire. To address this difficulty, it is of great emphasis organizations to maintain an appropriate management of human resources and personnel management, as this has great contribution in decision-making by both the employer and the employee.

\section{KEYWORDS}

People Management. Staff Turnover. Civil Construction.

ción y enel departamento de recursos humanos de una empresa en el sector de la construcción que la ciudad de Bagé / RS Zona, con la participación de veinte ocho empleados a través de del cuestionario. Para hacer frente a esta dificultad, es de grandes organizaciones de énfasis para mantener una adecuada gestión de los recursos humanos y gestión de personal, ya que esto tiene un gran aporte en la toma de decisiones por parte del empleador y el empleado.

\section{PALABRAS CLAVE}

Gestión de Personas Facturación. Staff. Construcción. 


\section{INTRODUÇ̃̃O}

Impactado pelo acesso ao crédito e o crescimento da renda per capita no Brasil, através de programas governamentais como "Minha Casa Minha Vida” entre inúmeros outros, o setor da construção civil atravessa, nestes últimos anos, talvez o melhor de sua história, uma situação ainda sem data para acabar. Segundo um estudo feito pelo Departamento Intersindical de Estatística e Estudos (Dieese) existe em 2013 uma expectativa de crescimento de $2 \%$ acima do Produto Interno Bruto que será entre 3 e $4 \%$.

Na Região da Campanha, mais precisamente em Bagé e Candiota, onde foi desenvolvido o trabalho, o atual momento econômico condiz com esta realidade e a construção civil transcende os mais otimistas índices de crescimento.

De acordo com a forma e maneiras adotadas nos trabalhos realizados pelas empresas da construção civil, se faz necessário compreender os fenômenos da rotatividade de pessoas em seus cargos. Seja por um momento vivenciado pela empresa, seja pelas novas formas de conceber e trabalhar com a mão de obra local e não local, ou simplesmente pela forma de desenvolver os trabalhos por meio das etapas da construção que facilitam ou dificultam o aumento de saída dos profissionais e a entrada de outros para desenvolverem as atividades.

Sabe-se que os motivos dos desligamentos ocorrem por meio de um fenômeno que é determinado por decisões das empresas e também por parte dos empregados que são:

Do lado das empresas, as demissões são devidas a variações no ciclo econômico, mudanças tecnológicas, reestruturação de quadros, inadequação dos trabalhadores, custo do trabalho e outros fatores. Do lado dos trabalhadores, os pedidos de demissão decorrem de mudança de município, busca de melhores salários, insatisfação no trabalho e razões ligadas à idade, saúde e família.
Diante das dificuldades encontradas pelas empresas estudadas em nossa região em relação à rotatividade de pessoal, esta pesquisa é importante para definir e apontar possíveis soluções que venham contribuir para a diminuição destes problemas no setor.

Com o aumento significativo de canteiros de obras em andamento nesta região, temos como resultante o aumento da oferta de trabalho e consequentemente uma maior oferta de renda por parte das empresas para com seus colaboradores. Esta premissa economicamente positiva tem como contrapartida o aumento da rotatividade de pessoal entre as empresas do ramo que por sua vez fomentam serviços de saúde, educação, lazer, entre outros fatores que se modificam constantemente em razão destes.

Também, com o aumento da geração de empregos, podem-se perceber inúmeras mudanças nas características do profissional, uma das principais é a busca de uma melhor qualidade de vida, renda, realizações de sonhos que são fatores que contribuem para a rotatividade de pessoal. Quando se tem muita procura, ganha a melhor e maior oferta, a empresa precisa de pessoas para frente de serviço, pois somente desta maneira consegue desenvolver seus objetivos. Com isso, a rotatividade se torna um fator significante para as empresas, pois onde a procura é grande, a competitividade é equivalente.

Os fatores mencionados anteriormente são considerados resultantes de um ótimo momento econômico do setor da construção civil. Porém, como toda ação gera uma reação, a rotatividade resultante é o grande conflito a ser solucionado com o menor trauma possível entre as partes interessadas. Esta pesquisa será de grande valia para entender e buscar formas de amenizar os efeitos da rotatividade para as empresas e seus colaboradores. Diante disso, busca-se a resposta para as seguintes indagações: 
Quais as principais causas da rotatividade de pessoal dentro da empresa da construção civil?

Verificar quais principais consequências ocasionadas por este fenômeno, tanto para a empresa quanto para o profissional.

Pesquisar quais mecanismos seria necessário para manter as pessoas na empresa por um período maior ou até o término de uma determinada obra.

Analisar se a cultura e o clima organizacional interferem na manutenção do pessoal nas obras.

\section{REVISÃO BIBLIOGRÁFICA}

É facilmente constatada que a estabilidade de pessoas que exercem determinadas funções e sua importância está diretamente ligada a reciprocidade de interesses entre empresas e seus funcionários e um dos principais interesses é o financeiro. Partindo desta premissa, as empresas têm a necessidade de manterem atualizadas e investirem em gestão e treinamento de pessoal, com isso, o êxito na diminuição da rotatividade pode ser mais facilmente alcançado.

Entende-se que treinamento tem como finalidade melhorar o desenvolvimento profissional do ser humano na sua organização e no desempenho das suas funções, além de ser o processo que visa à preparação e ao aperfeiçoamento das habilidades dos conhecimentos dos funcionários de uma organização.

De acordo com Chiavenato (1999) "O treinamento é uma maneira eficaz de delegar valor às pessoas, à organização e aos clientes. Ele enriquece o patrimônio humano das organizações". É importante lembrar que existe uma diferença entre treinamento e desenvolvimento das pessoas. Entende-se que o treinamento tem a finalidade de melhorar as habilidades do profissional no desempenho de suas funções. Já o desenvolvimento de pessoas tem o foco voltado a no- vos cargos a serem abertos na organização com novas capacidades e habilidades a serem aprendidas pelo empregado.

A estabilidade do profissional na empresa pode ser considerada como sendo a manutenção do mesmo no desenvolvimento das suas atividades, ao passo que a rotatividade de pessoal seria os desligamentos do profissional da execução das atividades. Mais especificamente, rotatividade pode ser considerada como sendo a diferença entre o número de profissionais que entram e saem da mesma empresa.

Chiavenato (1998, p. 176), afirma que:

Assim sendo, a rotatividade é a diferença entre a entrada e a saída de profissionais, o que pode ou não dificultar no desenvolvimento das metas ou atividades que a empresa tem a cumprir.

De acordo com Chiavenato (Chiavenato, 2000, P. 178):

Esta rotatividade pode ter vários fatores, mas antes vale ressaltar que define-se rotatividade de pessoal ou turnover como o fluxo de entrada e saída, isto é, uma flutuação de pessoal entre uma organização e seu ambiente.

0 diferencial desse estudo é que a pesquisa referente à rotatividade de pessoal em empresas do ramo da construção civil, pouco se tem falado e consequentemente estudado, justamente um dos ramos industriais que mais está crescendo e desenvolvendo de acordo com pesquisas realizadas pelo Instituto Brasileiro de Geografia e Estatística (IBGE).

A rotatividade é considerada um problema para muitas organizações, especialmente no que se re- 
fere às reposições de pessoal, os custos são grandes para o empregador que investiu em treinamentos para os trabalhadores, pois o investimento acaba não tendo resultado com a constante troca de trabalhadores.

Existem casos onde a rotatividade é “aceitável”, por exemplo, em empresas de Call Center, onde quanto maior tempo de exposição dos profissionais, podem gerar mais gastos relacionados à saúde, pois os profissionais passam grande parte do tempo sob pressão do trabalho desempenhado.

Neste sentido as empresas da Construção Civil, também, se encontram no benefício da rotatividade, principalmente quando as etapas nas construções são de maior demanda de mão de obra diferenciada e em um curto período de tempo de execução. Exemplo: obras de prazo determinado (CINTRA e PEDROSO, 2010).

Quanto à questão da rotatividade, ainda, percebe-se uma característica importante, que é a cultura por parte dos empregados em relação ao tempo de desenvolvimento de atividades em uma determinada empresa que não passam de dois anos de registro. Assim como demonstra Orellano (2000, p. 88):

Uma manifestação dessa característica é a grande porcentagem de trabalhadores que não chega a acumular dois anos de tempo de serviço na mesma empresa. Mesmo considerando apenas os trabalhadores com carteira assinada, a média dessa porcentagem no Brasil foi de $48,6 \%$ nos últimos anos, segundo as informações disponíveis na Relação Anual de Informações Sociais (RAIS).

Com isso, percebe-se que apenas aproximadamente $50 \%$ dos profissionais registrados na Carteira de Trabalho conseguem alcançar mais de dois anos na mesma empresa, o que constitui um alto número de rotatividade de profissionais.
Ao se falar em rotatividade há a necessidade de compreensão de como esta se dá nas empresas, em outras palavras, como é calculado o índice de rotatividade, as fórmulas e a concepção destes e as formas de lidar e trabalhar com os dados obtidos e apresentados.

0 índice de rotatividade pode ser calculado de duas formas: a primeira via percentual dos profissionais que estão circulando na empresa e o segundo que calcula diretamente os desligamentos de acordo com a perda de profissionais e suas possíveis causas.

Primeiramente, o índice de cálculo por meio do percentual deve-se ter os valores das admissões e demissões e tem de ser realizado da seguinte forma: associa-se o valor das admissões e demissões, dividindo por dois, posteriormente, multiplica-se por 100 a fim de calcular o percentual. E para obter o valor total do resultado obtido, ainda se divide pelo efetivo médio dos profissionais da empresa tendo assim o índice percentual da rotatividade de pessoal, de acordo com a figura abaixo (NICOLETI e ANDRADE, 2008).

Figura 1 - da Rotatividade Cálculo do índice percentual

Índice de rotatividade $=\frac{\frac{\text { Admissões }+ \text { Demissões }}{2} \times 100}{\text { Efetivo médio }}$

Fonte: Revista Olhar Científico - FAAr.

E para calcular apenas o índice de rotatividade em que se buscam posteriormente as suas possíveis causas e consequências na empresa, se realiza da seguinte forma: divide-se o valor das demissões multiplicado por cem ao número do efetivo médio da empresa, assim como na figura a seguir: 


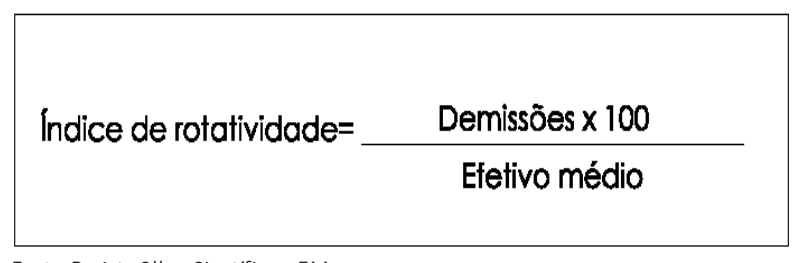

Fonte: Revista Olhar Científico - FAAr.

Portanto, para se realizar o índice de rotatividade de pessoal, existem duas formas conhecidas, a primeira encontra o percentual e a outra que trabalha com o índice de rotatividade. Dependendo da necessidade da empresa é realizado de uma ou outra forma o encontro do resultado do índice de rotatividade.

Quanto às questões da rotatividade de pessoas, outros fatores necessariamente envolvem a empresa e o contexto de uma forma geral. Alguns fatores podem facilitar ou atenuar esse índice, entre eles a cultura e o clima de organizações, a realização dos processos de recrutamento e a seleção dos profissionais entre outros.

\subsection{CULTURA E CLIMA ORGANIZACIONAL}

Como já se viu anteriormente, a cultura e o clima do local em que se realizam as atividades profissionais podem influir na rotatividade de pessoas, seja por uma característica da organização ou uma cultura e clima que estão se instituindo na mesma.

Quando uma organização assume vida própria, independente de seus fundadores ou qualquer de seus membros, ela adquire a imortalidade. A institucionalização opera para produzir uma compreensão comum, entre os membros da organização sobre o que é o comportamento apropriado. Partindo desta noção é que se compreende a cultura organizacional.

Ao se estudar os procedimentos organizacionais, um dos fatores essenciais para a compreensão dos fenômenos trata-se da subjetividade humana, em outras palavras, quando se está desenvolvendo atividades voltadas aos relacionamentos interpessoais, é de suma importância compreender que são os indivíduos que as compõe e por isso são circundadas de subjetividade.

De acordo com Moura (1995, p. 4):

A cultura é um sistema de crenças (como as coisas funcionam) e valores (o que é importante) compartilhados (vivenciado por todos) e que interagem com (penetrações nos sistemas e subsistemas) as pessoas, as estruturas e mecanismos de controle para produzir (efeitos) as normas de comportamento características daquela organização (como fazemos as coisas por aqui).

Já para Schein (1998., p. 4):

Cultura organizacional é o conjunto de pressupostos básicos que um grupo inventou, descobriu ou desenvolveu ao aprender como lidar com os problemas de adaptação externa e integração interna e que funciona bem o suficiente para serem considerados válidos e ensinados a novos membros como a forma correta de perceber, pensar e sentir em relação a esses problemas.

Quanto à subjetividade humana e social considera-se que a cultura pode ser conhecida como crenças, práticas culturais, valores, instituições, regras, entre outros que permeiam e identificam a sociedade e os seres humanos e sociais.

A cultura organizacional está inerente às questões hierárquicas da empresa, como as dificuldades que esta possa estar enfrentando, as pressões do dia a dia dos setores e administração da mesma. Pode-se compreender, ainda, que seja a cultura que traduz para os indivíduos sociais a imagem que o restante da sociedade dela possui ou imagina por meio das percepções e simbologias utilizadas.

Para melhor exemplificar os fatores de cultura e clima organizacional pode-se considerar o seguinte exemplo que acontece nas empresas de construção civil: para os profissionais e demais instâncias do conhecimento social, as mulheres vêm ganhando espaço no desenvolvimento dos trabalhos desse tipo de mão de obra, mas o que se sabe que está enraizado na 
cultura das mesmas é o fato dessa afirmativa da mão de obra feminina pouco acontecer e quando ocorre, logo existe uma tendência à discriminação e podem vir a sofrer dificuldades na execução das suas atividades (CINTRA e PEDROSO, 2010).

Chiavenato (1994, p. 52) afirma que:

\begin{abstract}
A cultura representa o ambiente de crenças e valores, costumes, tradições, conhecimentos e práticas de convívio social e de relacionamento entre as pessoas. A cultura significa o comportamento convencionalizado e aceito pela sociedade e provoca enorme influência e condicionamento sobre todas as ações e comportamento das pessoas. Sob um ponto de vista genérico, a cultura consiste de padrões explícitos de comportamentos adquiridos e transmitidos ao longo do tempo e que constituem uma característica própria de cada sociedade. Através da cultura a sociedade impõe suas expectativas e normas de conduta sob seus membros condicionando-os a se comportarem de maneira socialmente aceitável aos seus padrões, crenças, valores, costumes e práticas sociais.
\end{abstract}

Ainda a fim de conceituar o clima organizacional se pode considerar segundo Soares $(2005$, p. 8 )

\begin{abstract}
Existem várias definições do termo, onde a mais utilizada entende-se como um conjunto de propriedades mensuráveis no ambiente de trabalho percebido, direta ou indiretamente pelos indivíduos que vivem e trabalham nesse ambiente e que influencia a motivação e o comportamento dessas pessoas.
\end{abstract}

Portanto, o clima organizacional pode ser conceituado de várias maneiras, a depender da visão de cada autor ou estudioso do assunto. Mas de uma forma ampla compreende-se como sendo o ambiente vivenciado pelos profissionais e percebido pelos mesmos de forma direta ou indireta e interferindo nas relações interpessoais e da produtividade dos profissionais, vir a ser um problema para as organizações em termos de desenvolvimento das atividades de cada um (SOARES, 2005).

Para Bennis (s.d.) o clima é um conjunto de valores e/ou atitudes que podem afetar a maneira pela qual as pessoas relacionam-se uma com as outras.
Conforme Luz (s.d.) O clima organizacional reflete o grau da satisfação dos colaboradores da organização em um determinado momento.

O clima organizacional pode ser visto, também, como um conjunto de fatores que interferem na satisfação ou descontentamento no trabalho. Entende-se por fatores de satisfação àqueles que demonstram os sentimentos mais positivos do colaborador em relação ao trabalho, tais como: a realização, o conhecimento, o trabalho em si, a responsabilidade e o progresso. Por fatores de descontentamento, temos aqueles que contribuem com uma conotação negativa, do ponto de vista do colaborador, tais como: as políticas e administração, a supervisão, o salário e as condições de trabalho (CINTRA e PEDROSO, 2010).

Na opinião de Chiavenato (1994, p. 53) "O clima organizacional é favorável quando proporciona satisfação das necessidades pessoais dos participantes, produzindo elevação do moral interno. É desfavorável quando proporciona frustração daquelas necessidades".

Segundo Chiavenato (1994), o clima organizacional evidencia a motivação, o desempenho humano e a satisfação no trabalho, ele cria certos tipos de expectativas cujas consequências se seguem em decorrência de diferentes ações. As pessoas esperam certas recompensas, satisfações e frustrações na base de suas percepções do clima organizacional. Essas expectativas tendem a conduzir à motivação.

\subsection{RELAÇÕES ENTRE CULTURA E CLIMA ORGANIZACIONAL}

Entre cultura e clima há uma relação de causalidade. A cultura sendo a causa e o clima a consequência. O clima e cultura são fenômenos intangíveis, apesar de se manifestarem de forma concreta.

Apesar disso vemos a cultura por meio de arquiteturas, vestuários, comportamento de colaboradores, ela irá se tangibilizar através do relacionamento da empresa com seus parceiros comerciais. 
Clima é um fenômeno temporal, refere-se aquele dado momento. Já a cultura é decorrente de práticas recorrentes ao longo do tempo.

\subsection{EMPRESAS DE CONSTRUCÕ̃O CIVIL}

As empresas de construção civil são consideradas molas propulsoras da economia brasileira, ou seja, são de grande importância para o desenvolvimento tanto dos indivíduos como para a população de um modo geral.

Além das referidas empresas envolverem o setor da indústria específica da construção civil, envolvem, também, demais ciclos de desenvolvimento tais como produtores de máquinas e equipamentos e empresas responsáveis por contratação de mão de obra especializada ou operacional (CINTRA e PEDROSO, 2010).

Pode-se considerar, também, que este tipo de empreendimento tem como fonte de profissionais a classe média baixa da economia brasileira, em especial aos indivíduos do sexo masculino e com baixa instrução de escolaridade ou até mesmo sem nenhuma instrução e claro, com força física e desprendimento familiar, histórico regional devido às mudanças e transferências de cidades, estados e até países (CINTRA e PEDROSO, 2010).

Atualmente as empresas da construção civil têm ganhado um imenso espaço no desenvolvimento brasileiro em comparação com décadas e períodos históricos anteriores, considerando o desenvolvimento econômico e social ao qual o Brasil está vivenciando.

Ao mesmo tempo em que as empresas de construção civil ficam obrigadas a respeitar novos valores em seu desenvolvimento e aprimoramento das tecnologias em vigor, os profissionais que nelas trabalham também se encontram no momento de realizar novos treinamentos e desenvolver outras habilidades não exigidas até então.
Neste sentido, Fujimoto e Paulon (2009, p. 3) nos dizem que:

As inúmeras mudanças exigidas das habilidades do trabalhador, neste final de século, concomitantemente com a evolução da tecnologia, fazem com que os mesmos sejam facilmente descartáveis no mercado de trabalho. Isto, devido ao fato de que este trabalhador, de baixa escolaridade, não reúne condições e muito menos tem chances para aprender sozinho uma profissão, quanto mais uma qualificação ou mesmo uma requalificação profissional.

\section{METODOLOGIA}

Para o desenvolvimento deste trabalho, o tipo de pesquisa utilizado foi a pesquisa bibliográfica e estudo de caso.

Foram entrevistados vinte colaboradores por meio de questionário aplicado no período de janeiro a abril de 2014.

A população entrevistada compreende operários ligados diretamente na construção civil como: pedreiros, serventes de pedreiro, instaladores hidráulicos, instaladores elétricos, gesseiros, carpinteiros, marceneiros e pintores.

Foram entrevistadas no mínimo duas pessoas de cada categoria acima mencionada em cada obra utilizada para a pesquisa.

O local escolhido para a pesquisa contempla duas obras em diferentes regiões, sendo uma na cidade de Bagé/RS, e outra no município vizinho de Candiota/RS.

A coleta dos dados pertinentes à pesquisa foi adquirida por meio de levantamento bibliográfico e com a aplicação de um questionário com indagações que tangem diretamente ao problema principal da pesquisa, que é a rotatividade de pessoal, buscando informações as mais coerentes para justificar/analisar o problema abordado. 
A análise e interpretação destas informações serão demonstradas por meio de gráficos, textos explicativos e comparação dos resultados obtidos, os quais seguem

\section{ANÁLISE E DISCUSSÃO DOS RESULTADOS}

Com a contribuição dos dados resultantes das entrevistas e aplicação do questionário, iremos analisar e discutir a problemática definida que vem atingindo diretamente as empresas do setor na nossa região.

O questionário aplicado aos trabalhadores abordou diferentes assuntos tais como: tempo de profissão, quanto tempo de trabalho na empresa, possibilidade de trabalho pela empresa em outros municípios ou estados, renda familiar, grau de escolaridade e grau de satisfação entre outros.

Para auxiliar na leitura destes dados, foi adotado o uso de figuras gráficas (Figuras 3 a 7) como forma de melhor explicitar as informações coletadas.

Figura 3 - Gráfico da satisfação salarial das categorias atuantes na empresa

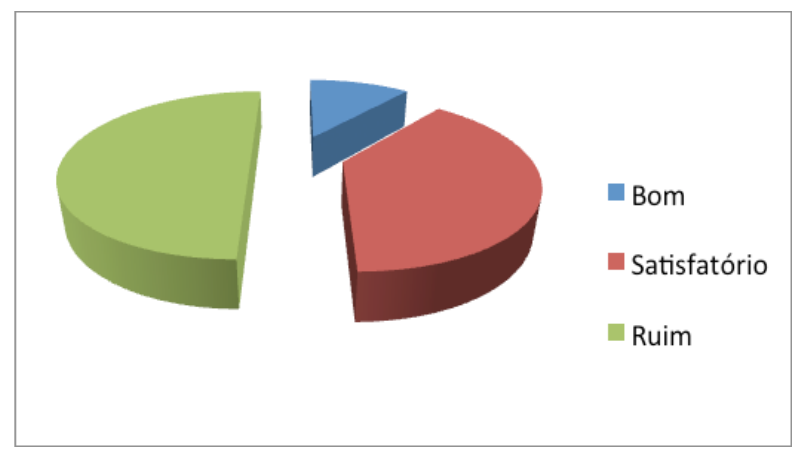

Fonte: dados primários - 2014.

Com o auxílio da Figura 3, pode-se afirmar que um dos principais motivos da rotatividade de pessoal na empresa estudada está no grau de satisfação salarial da categoria, pois se pode observar que a grande maioria dos entrevistados aponta para uma renda salarial de satisfatória para ruim, sendo quase que in- significante o percentual que acena para uma renda considerada como boa.

No quesito, quase que na totalidade dos entrevistados reforçaram de forma imprescindível a necessidade de o cônjuge contribuir com a renda familiar, ocasionando outros conflitos relatados como a dificuldade na criação e educação dos filhos que por sua vez necessitam de creches e escolas, enquanto os pais saem de casa para trabalhar. Salvo alguns serventes de pedreiro que por serem geralmente mais jovens, ainda se encontram solteiros.

Assim sendo, o resultado acima vem reforçar a afirmação de Chiavenato (1998) o qual relata que quando se tem muita procura, a oferta financeira é melhor e mais atrativa para os trabalhadores que estão sempre em busca de uma melhor qualidade de vida.

Ainda quanto à insatisfação apontada acima, esta vem corroborar com o que diz Cintra e Pedroso (2010) em relação à Cultura e Clima organizacional, os quais afirmam que o fator de descontentamento contribui como uma conotação negativa do ponto de vista do colaborador a respeito das políticas de administração, supervisão, salário e as condições de trabalho na empresa.

Para reforçar as afirmações acima, buscou-se na entrevista saber qual é a renda familiar média recebida pelos integrantes das famílias dos entrevistados.

$\mathrm{Na}$ Figura 4, a seguir, podem-se distinguir estes parâmetros de acordo com cada categoria do entrevistado. Buscou-se no valor do salário mínimo nacional o fator base para cálculo de quantos salários cada família de determinado colaborador recebe.

Foram entrevistados pedreiros, carpinteiros, serventes, marceneiros, eletricistas, instaladores hidrossanitários e gesseiros, sendo os últimos dois os de maior renda familiar. Isto se justifica, também, pelo grau de instrução e cursos de treinamento recebidos para atuarem e desempenharem suas funções e consequentemente serem mais bem remunerados. 
Por meio destes dados, compreende-se a necessidade afirmada de que outros membros da família precisam participar para a complementação da renda dos entrevistados.

Figura 4 - Gráfico da renda familiar média dos funcionários entrevistados

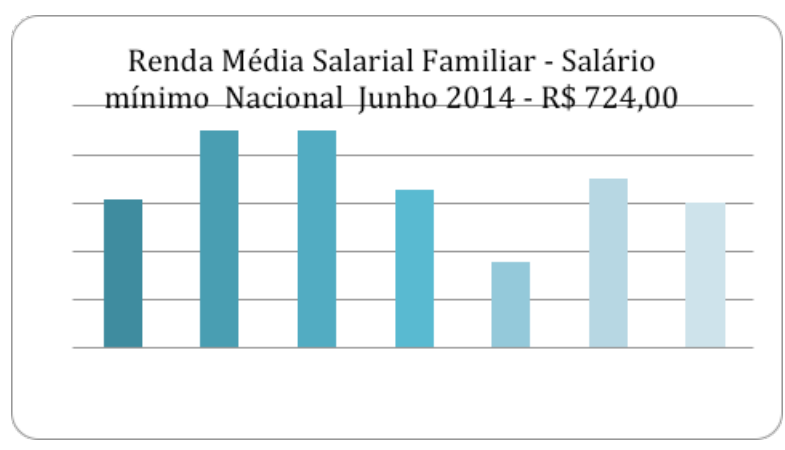

Fonte: dados primários - 2014

Outro dado interessante obtido com a aplicação do questionamento foi à importância de fatores extrassalariais de colaborarem com o aumento da permanência do colaborador na empresa. Como podemos observar na figura 5 abaixo, onde premiações, vales transporte e alimentação entre outros figuram como atrativos para que se compunha uma parceria mais duradoura entre as partes.

Figura 5 - Gráfico de benefícios que contribuem para a diminuição da rotatividade dos funcionários na empresa

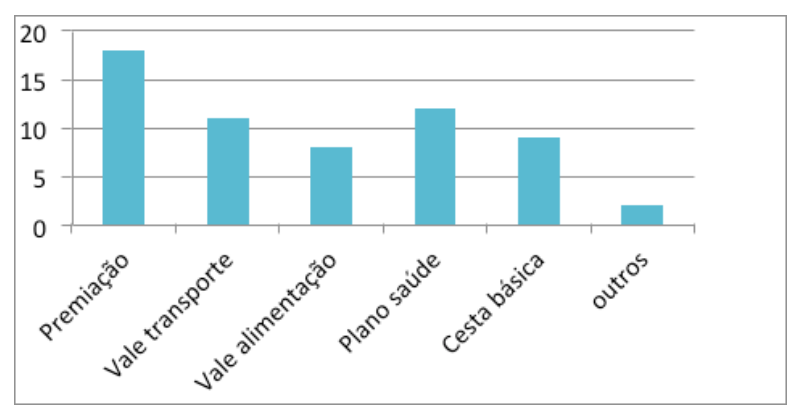

Fonte: dados primários - 2014.
Com o demonstrativo da Figura 6 abaixo, pode-se observar o baixo índice de escolaridade dos funcionários na construção civil. Ou seja, um problema cultural, nacional. Pois é praticamente impossível a iniciativa privada da construção civil amenizar este quadro, vez que, por se tratar de um problema desta natureza, exige altos investimentos em educação e treinamento, os quais são plausíveis e possíveis apenas para uma pequena faixa que compreende grandes incorporadoras altamente estruturadas, que possuem condições de oferecer este tipo de benefício de formação em educação como meio de amenizar a rotatividade de pessoal.

Neste quesito, fica clara a carência de escolas formadoras de mão de obra qualificada/especializada em nossa região.

Figura 6 - Gráfico do nível de escolaridade dos funcionários na empresa.

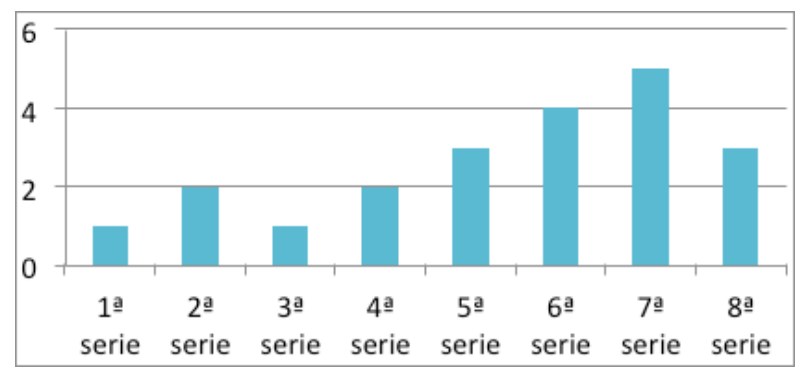

Fonte: dados primários - 2014

Foi analisado também, o tempo de registro de funcionários da empresa em questão, e os resultados condizem com a afirmação de Orellano (2006), o qual diz que no desenvolvimento de atividades de pessoal com registro no ramo da construção civil em geral, não passa de dois anos de empresa. A demonstração abaixo (Figura 7) comprova que mais de cinquenta por cento do pessoal com registro nas empresas do ramo, não chegam a atingir este índice de permanência com registro na empresa. Com isso, confirmam-se, também, os altos custos da rotatividade de pessoal com admissões (taxas, documentação, impostos) e demis- 
sões (impostos, multas e indenizações) que são consequências dessas formalizações.

Figura 7 - Gráfico de tempo de registro dos funcionários na empresa

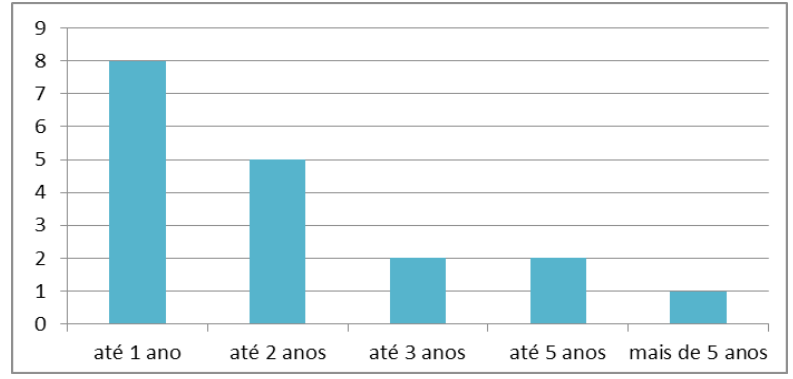

Fonte: dados primários - 2014

\section{CONSIDERACÕ̃ES FINAIS}

Sabe-se que a construção civil vem ganhando espaço e atenção das mais variadas formas de conceber o conhecimento. As ciências de uma forma geral vêm estudando os fenômenos e as consequências dos impactos causados pelas grandes obras e construções. Este artigo vem por sua vez explanar os estudos referentes aos impactos causados na vida das pessoas que trabalham ou dependem de alguma forma das empresas do setor da construção civil.

A rotatividade vem sendo um fenômeno comum nas empresas, e de um modo geral é notavelmente mais acentuada nas empresas que venham a trabalhar com etapas de atividades, assim como procedem às empresas de construção civil. São realizadas construções de etapas de uma determinada obra, constrói-se um andar sucessivo ao outro em um prédio, a base e posteriormente o telhado em uma casa, assim como também é realizado a construção de uma usina por frentes de serviço, por exemplo: primeiramente são realizados os serviços topográficos, medições e posteriormente os serviços de escavações e concretagem das partes pertinentes ao projeto.
O fato é que as obras sendo realizadas por etapas favorece o acontecimento da rotatividade, já que a mão de obra da topografia é diferente da mão de obra da concretagem, ou em outras palavras, a cada etapa da construção, novos profissionais são contratados, enquanto aqueles que terminaram a etapa anterior muitas vezes estão sendo relocados em outras etapas ou simplesmente desligados da empresa.

Aliados a estes fatores, pode-se perceber no decorrer da pesquisa realizada que, como possíveis causas da rotatividade de pessoas dentro de uma determinada empresa da construção civil, pode-se creditar à busca por uma melhor colocação hierárquica ou por uma melhor qualidade de vida.

Por outro lado, como consequência para as empresas podem ser considerados os altos valores pagos ao governo em forma de impostos referente a contratação e demissões dos profissionais, além de que no atual momento vivenciado da construção civil no país onde existe a enorme dificuldade de se conseguir mão de obra qualificada para exercerem as atividades em questão, sendo necessário por não raro as vezes a contratação de pessoas de outros estados, gerando com isso altos valores demandados para transporte, alimentação e estadia entre outros.

Entretanto, na busca de fazer com que a rotatividade de pessoas possa ser diminuída, ou ainda que seus efeitos não sejam ameaçadores para o desenvolvimento das atividades dos profissionais ou prejudiciais para a empresa em questão, faz-se como sugestão que as empresas venham a investir mais em formação, qualificação profissional e pessoal tanto para os líderes de equipe, quanto para os setores de recrutamento e seleção para encontrarem o melhor perfil para o desenvolvimento das atividades para o sucesso de ambos nas organizações.

Este trabalho específico vai requerer o desenvolvimento das habilidades em relacionamento interpessoal e qualificação profissional, tendo necessa- 
riamente, o apoio de uma equipe multiprofissional na busca de encontrar e desenvolver funções e soluções. 0 que resultaria em profissionais satisfeitos em seus anseios e com objetivos alcançados.

\section{REFERÊNCIAS}

ARAÚJO, Geraldino Carneiro; DIAS, Edilaine Mendes. Estudo sobre os processos de recrutamento e seleção em agroindústrias: uma análise de dois estudos de casos. Disponível em: <http://www.sober.org.br/ palestra/9/833.pdf>. Acesso em: 22 mar. 2014.

BENNIS, W. A Formação do Líder. São Paulo: Atlas, 162 p, 1996.

CHIAVENATO, I. Recursos Humanos. 6. ed. São Paulo: Atlas, 2000.

CHIAVENATO, I. Gestão de Pessoas:O novo papel dos recursos humanos nas organizações. $6^{\text {a }}$ tiragem. Rio de Janeiro: Campus, 1999

CHIAVENATO, Idalberto. Recursos Humanos. 5.ed. São Paulo: Atlas, 1998.

CHIAVENATO, I. Gerenciando Pessoas. $3^{a}$ edição. São Paulo: Makron books,1994.

CINTRA, Gisele Amaral; PEDROSO, Reginaldo. Rotatividade de pessoal: um estudo de caso. 2010. Disponível em: <http://olharcientífico.kinghost.net/index>. Acesso em: 25 fev. 2014.
FUJIMOTO, Aparecido; PAULON, Vladimir Antônio. Formação e treinamento de trabalhadores na construção civil: qualificação profissional, 2009. Disponível em: <http://www.bibliotecadigital.unicamp.br/ document/>. Acesso em: 3 abr. 2014.

LUZ, Ricardo. Gestão do Clima Organizacional. Rio de Janeiro: Qualitymark, 2003.

MOURA, Paulo C. O Beneficio Das Crises. São Paulo: Mauad Editora, 1995.

NICOLETI, Gerson Gilberto; ANDRADE, Hélio AIves de. Rotatividade de pessoal: estudo de caso na empresa Cooper - coop. de produção e abast. vale do Itajaí. Disponível em: <http://unibes.edu. br/unibes/virtual>. Acesso em 28 de mar. 2014.

ORELLANO, Verônica I. Fernandes. Evolução da rotatividade da mão-de-obra da região metropolitana de São Paulo no período de 1986-2000. Disponível em: <http://ppe.ipea.gov.br/index.php/ ppe/article/viewfile>. Acesso em: 5 abr. 2014.

SCHEIN, Edgar. Organizational Culture and Leadership. San Francisco, Jossey Bass Publications. 2a Ed. 1989

SOARES, Leandro da Silva. Métodos de Qualidade Aplicados à Gestão do Clima organizacional. Rio de Janeiro, 2005. Disponível em: <http:// www.fecra.edu.br/adami/arquivos/culturaeclimaorganizacionalapostila>. Acesso em: 15 fev. 2014. 